\title{
Management Substitution Patterns in The Current Era
}

\author{
Mansour Karami ${ }^{1}$, Ali Karimi ${ }^{2}$, Abdolrahim Jamshidi ${ }^{3}$ \\ ${ }^{1}$ University lecturer and employee of Fars Province Industry, Mining and Trade Organization. \\ Mansourkarami3@gmail.com \\ ${ }^{2}$ University lecturer and member of the Institute of Money and Credit. \\ Arr_karimi@yahoo.com \\ ${ }^{3}$ Master of Public Administration and Employees of Fars Province Industry, Mining and Trade \\ Organization. \\ Rahim.jamshidi95@gmail.com
}

\section{ARTICLE INFO}

\section{Keywords:}

Organizational

Planning substitution

Employee empowerment

Delegation of authority

Self-management

\begin{abstract}
Human beings are central issues in management and organization. In today's world, knowledge-based economy is considered, and in this view, human resources are regarded as intellectual property, spiritual capital, and the most valuable capital of an organization. The proper management of human resources will increase the productivity and positive economic outcomes. Due to the shortage of management forces and the increasing need for organizations for more capable and more skilled managers in the coming years, attention to management alternatives is essential for these needs. Management succession planning is one of the most important issues in the planning of human resources to fill the gaps and to meet the requirements of key and sensitive parts of the organization at the management level. In this paper, four main perspectives of management substitution patterns - education and empowerment, the basis of employee maturity, strong organizational culture, delegation of authority and self-management - have been discussed and finally, a conceptual model of these perspectives (as article innovation) is extracted and is presented.
\end{abstract}

\section{Introduction}

An organization is a social system that, within a broader system-the society-is created intuitively and coordinated by management and realizes its goals and objectives with a relatively fixed membership (Rasouli, 2005). In general, the organization consists of five elements: (1) the organization is always composed of individuals; (2) these people are connected and interconnected; (3) these interrelations can be regulated; (4) All individuals in organizations have specific goals that affect their performance, and 5) These relationships allow the organization to achieve common goals and motivate members of organizations to achieve their individual goals and achieve the goals of the (organization. Creed, 2009). According to Peter Drucker, the twenty-first century is a century of knowledge economy. In this economy, intellectual property and human capital are the most important capital of an organization, and the potential success of organizations is rooted in their intellectual capacity (Holton, 2000). Paradigms and intellectual frameworks and profound changes in human resources Has paved the way for making more use of the power and expertise of the 
organization's employees (Weiss, 2005). Therefore, in the current era, management of these organizational capital or succession patterns for the management of staff is inevitable (Ebrahimi, 2005). Productivity as one of the main factors in the competitiveness and survival of the organization, strongly influenced by the ability of capital Organizational capital plays an indelible role in the growth and development of organizations and society. In general, the planning of substitution patterns is the systematic application of individuals to the organization according to the planning (Alvarez, 2004)

Today, in organizations due to reduction of management forces and the need for more skilled and competent managers, this problem must be created by creating succession management models (Abbaszadegan, 2006). In the following, four main perspectives of management succession patterns are examined.

\section{Training and Empowerment, Influencing the Maturation of Employees}

Education is a military that can create the power of exclusion and knowledge of knowledge in its users. The training process consists of four steps: (a) literacy: the exclusion of marks; (b) learning science: the development of knowledge-based; and (c) the birth of science; (d) the creation of analytical power (Connelly, 2009). The training introduces the empowerment of the staff and leads to the development of an organizational structure for dynamism, modification of organizational culture, the creation of analytical power in managers, identifying barriers to empowerment, and developing policies and strategies to deal with them (Alvarez, 2004). Employee empowerment is the empowerment of human resources, ie, the creation of a set of capacities in the staff to enable them to create added value in organizations and to effectively and efficiently play their roles and responsibilities within the organization (Rouiller, 2007). Also, career rehabilitation A process in which the manager helps employees to be capable The goal is to provide the best sources of thought relevant to each field of the organization's performance; in other words, it aims to apply the most influential employees in the most appropriate manner. The results of empowerment of employees can be seen to increase job satisfaction and customer satisfaction, which is based on the change in organizational culture (Holton, 2000). As technology progresses and firms move toward flattening and eliminating middle layers of management, empowerment is important. Will find something special. In general, the benefits of empowerment can be divided into two categories: 1. Organizational Benefits: Productivity Rising; 2. Individual Benefits: Increase employee experience and prepare for management positions; because empowerment inspires sense of strength and trust. The empowerment of individuals is the prosperous potential of human beings (Alvarez, 2004). Given that today's world is a competitive world and is ready to survive in organizations, individuals must be able to perform their duties without having to manage others. To survive the organization and the community (Connelly, 2009). Hence, the maturity of employees in the light of their empowerment can be seen as a management succession patterns and the need to increase management and centralized management in organizations reduction. (Holton, 2000) (figure 1). 


\begin{tabular}{|c|c|c|c|c|}
\hline \multicolumn{2}{|c|}{ Employees training } & $\begin{array}{c}\text { Make changes in the } \\
\text { organization }\end{array}$ & Individual effects & \\
\hline Education & Withdrawal & $\begin{array}{l}\text { 1-Organizational } \\
\text { structure evolution. } \\
\text { 2- Adjustment of } \\
\text { culture. }\end{array}$ & $\begin{array}{l}\text { 1-Enhance } \\
\text { experience } \\
\text { 2-Increase } \\
\text { satisfaction }\end{array}$ & \multirow{3}{*}{ 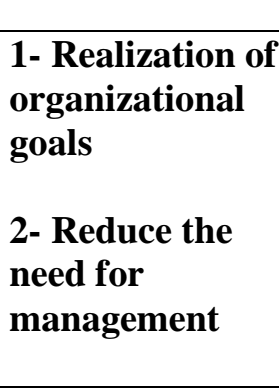 } \\
\hline Learning & & $\begin{array}{l}\text { 3- Increase power of } \\
\text { analyzing for manager. }\end{array}$ & & \\
\hline Science creation & \multirow{2}{*}{$\begin{array}{l}\text { Endogenou } \\
\mathrm{s}\end{array}$} & $\begin{array}{l}\text { 4- Identifying barriers to } \\
\text { employee }\end{array}$ & $\begin{array}{c}\text { Organizational } \\
\text { impacts }\end{array}$ & \\
\hline Analysis power & & empowerment. & $\begin{array}{l}\text { 1- Customer } \\
\text { satisfaction } \\
\text { 2- Efficiency }\end{array}$ & \\
\hline
\end{tabular}

Figure 1: Training and Empowerment, Influencing the Maturation of Employees

\section{Creating a strong organizational culture}

Culture means common and fixed beliefs and values that develop within an organization over time (Weiss, 2005). According to this definition, organizational culture is the beliefs, attitudes and values that are commonly found in an organization, and to the creation of behavioral norms leads, as we all know, to each person who has a personality that is a series of relatively stable and stable characteristics. An organization also has a personality called organizational culture (Yilmaz, 2008). Edgeard Shine has three levels for organizational culture, the first level includes behaviors and tools or physical charts; the second level involves feelings and perceptions, and the third level involves hypothetical (Weiss, 2005). Considering the characteristics of culture (learnable, social, mental and imagined, satisfactory, and consistent and communicative), it can be concluded that human behavior relies principally on cultural beliefs and the root in different beliefs, such as historical, political, geographical, religious, etc. (Scherer, 2007), the reasons for the creation of organizations, their place in society and its success factors, cause the formation of different cultures. It is spoken with an organizational culture, the dominant culture of the organization, because organizations have a number of subcultures and a dominant culture in the organization (Yilmaz, 2008). The dominant culture represents the core values that are maintained and pursued by most members of the organization, and since individuals and groups work in organizations, each has a subculture in the heart of the culture of the organization. Whatever the key values of the organization are accepted and the employee's commitment to those values is higher, culture is stronger and more appropriate. All organizations have a culture but do not have equal impact on employees. The culture improves employee satisfaction and reduces the chances of leaving them (Scherer, 2007). This type of culture also increases the behavioral stability and reduces quitting, and as a result, it is a powerful tool as a substitute for formalizing the organization and even more so than formal structural control. Creating appropriate culture is the use of many techniques, such as socialization, participation and self-fulfillment in the organization (Yilmaz, 2008). From the results of appropriate culture, the high commitment of employees to their responsibilities and responsibilities in the organization, thus reducing the need for managerial management and approach to management substitution. (Weiss, 2005). Considering that culture is a suitable culture Accepted by most people, its acceptance can lead to the survival of the organization and, consequently, increase productivity and reduce the need for management forces (Yilmaz, 2008) (Figure 2). 


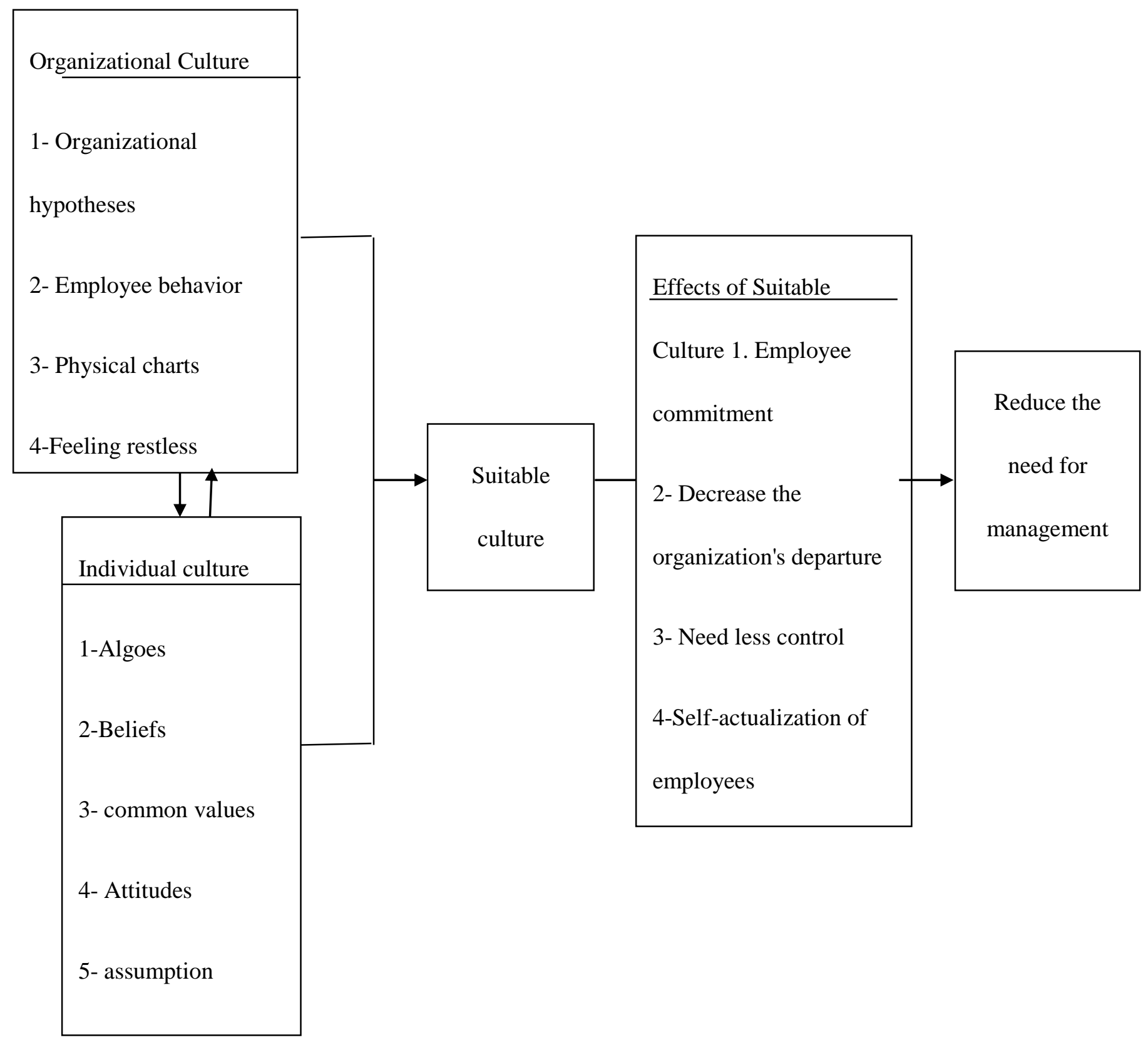

Figure 2: Creating a strong organizational culture

\section{Delegation of authority}

One of the manager's roles is the ability to work with and through others that applies to all managers in each organization and every location, and is also referred to as a definition for management (Ebrahimi, 2005). The delegation of powers is one of the dimensions of management, in which it gives the person the power and authority to make decisions in a specific area. Delegation of duties and responsibilities has significant outcomes and benefits: sharing information, knowledge, power, decision making and reward. (Kennedy, 2000). According to Martin Scott, excessive work is one of the key factors in the distress of managers (Scherer, 2007). The benefits of delegating power to individuals, members of the group and organization are as described in Table 1. 


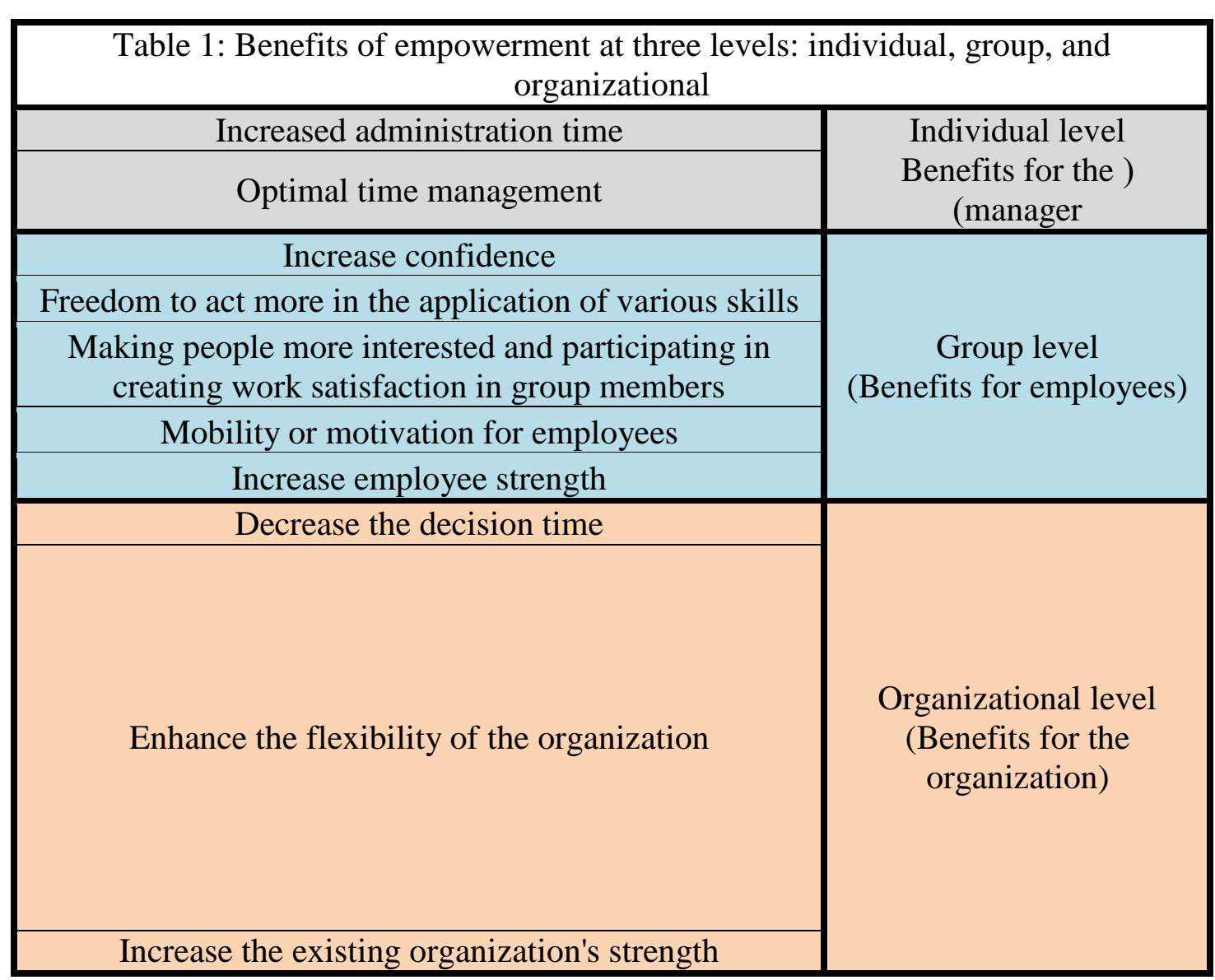

Advantages of delegating power to members of the group increase their managerial power and gradually can be as a successor to the manager in the context of the experience gained through voluntary delegation. The modern approach of today's organizations is selfcontributing to the conflict of engagement (Abdollahi, 2006). Clash involves doing things in an administrative time completely without any waste of time. While occupational engagement involves the entire life of the individual and the work of the staff, and after the end of the work, one is contemplating his own work, which is most often seen in successful people (Gordon, 2001). Empowerment is one of the most important skills, and today it plays an essential role in the success of organizations and in the direction of self-management of employees and changes in organizational structure and developing the people who have the right substitutes for management (Ebrahimi, 2005) (Figure 3). 


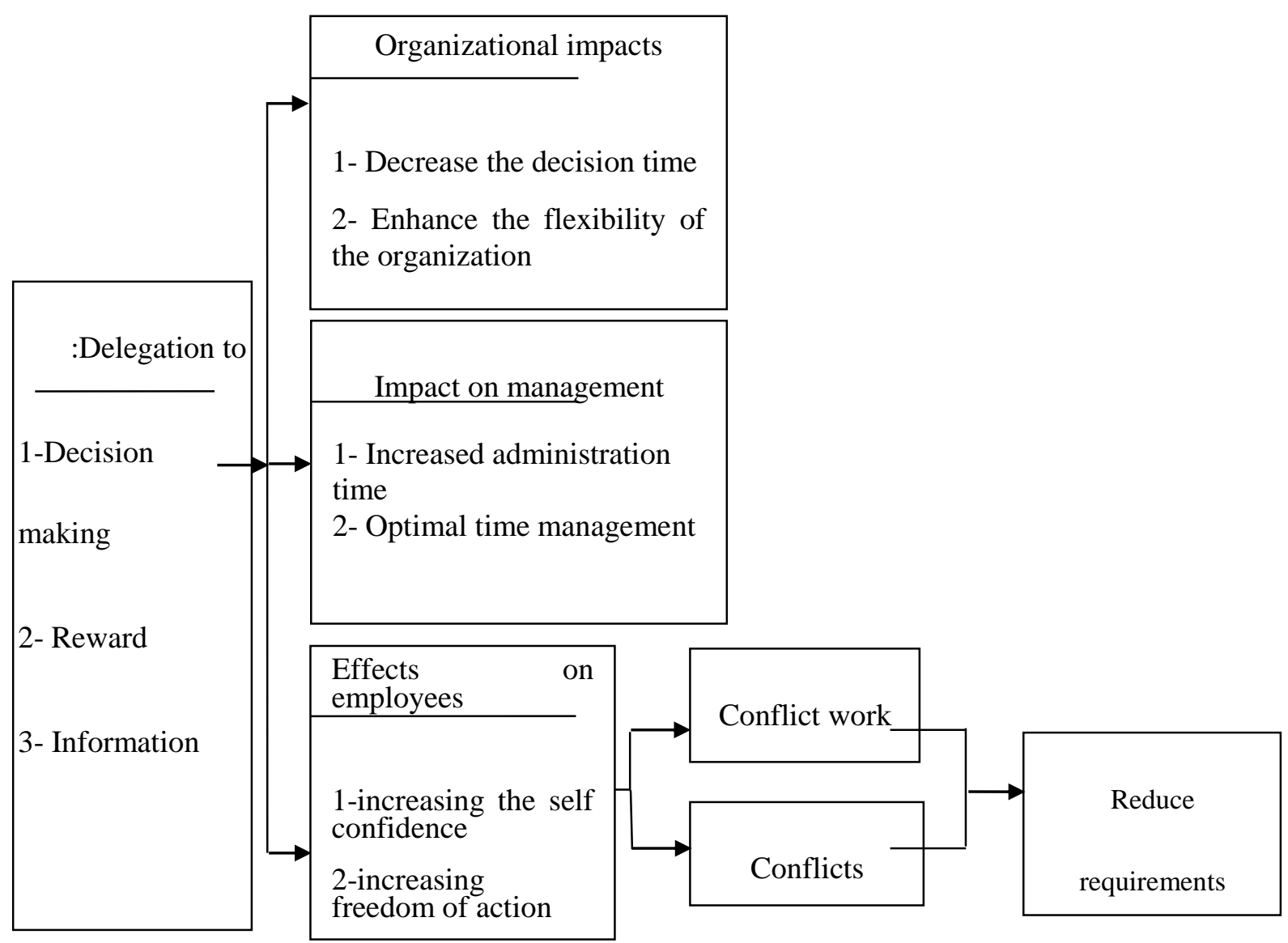

\section{Self-management}

Figure 3: Delegation

Behavioral self-management is the process of modifying its behavior through the systematic administration of stimuli, cognitive processes, and contingencies. (Creed, 2009). Selfmanagement of behavior mainly focuses on modifying behavior to change values, attitudes, or characters, and results from social epistemology. (Weiss, 2005). Self-management is a prerequisite for effective management of individuals, groups, organizations and communities (Abdallahi, 2006). To realize self-management, a number of areas are needed to create a platform for individuals to create self-esteem, self-esteem, self-esteem, and self-esteem. Creed, 2009). Self-perception is the basis of self-awareness. Respect for self is self-esteem. Respect for self-organization is the amount of respect for positive self-esteem; that is, one considers himself to be important, valuable, effective, and meaningful to the organization (Gordon, 2001). Self-confidence can lead to self-esteem, and the first factor contributing to it is the success of previous experiences (Abdallahi, 2006). In addition, other people's behavioral skills, encouragement from others and assessment of one's own emotional and physical condition can strengthen self-esteem. Self-management is based on social awareness and must be managed by managing environmental stimuli (reminding and attracting attention, information from personal observations, avoiding negative stimuli, seeking positive stimuli, individual targeting, etc.) Self-cultivating one (self-talk exercise, symbolic encoding) and creating a self-control phenomenon attempted to create it. (Creed, 2009). (Figure 4). 


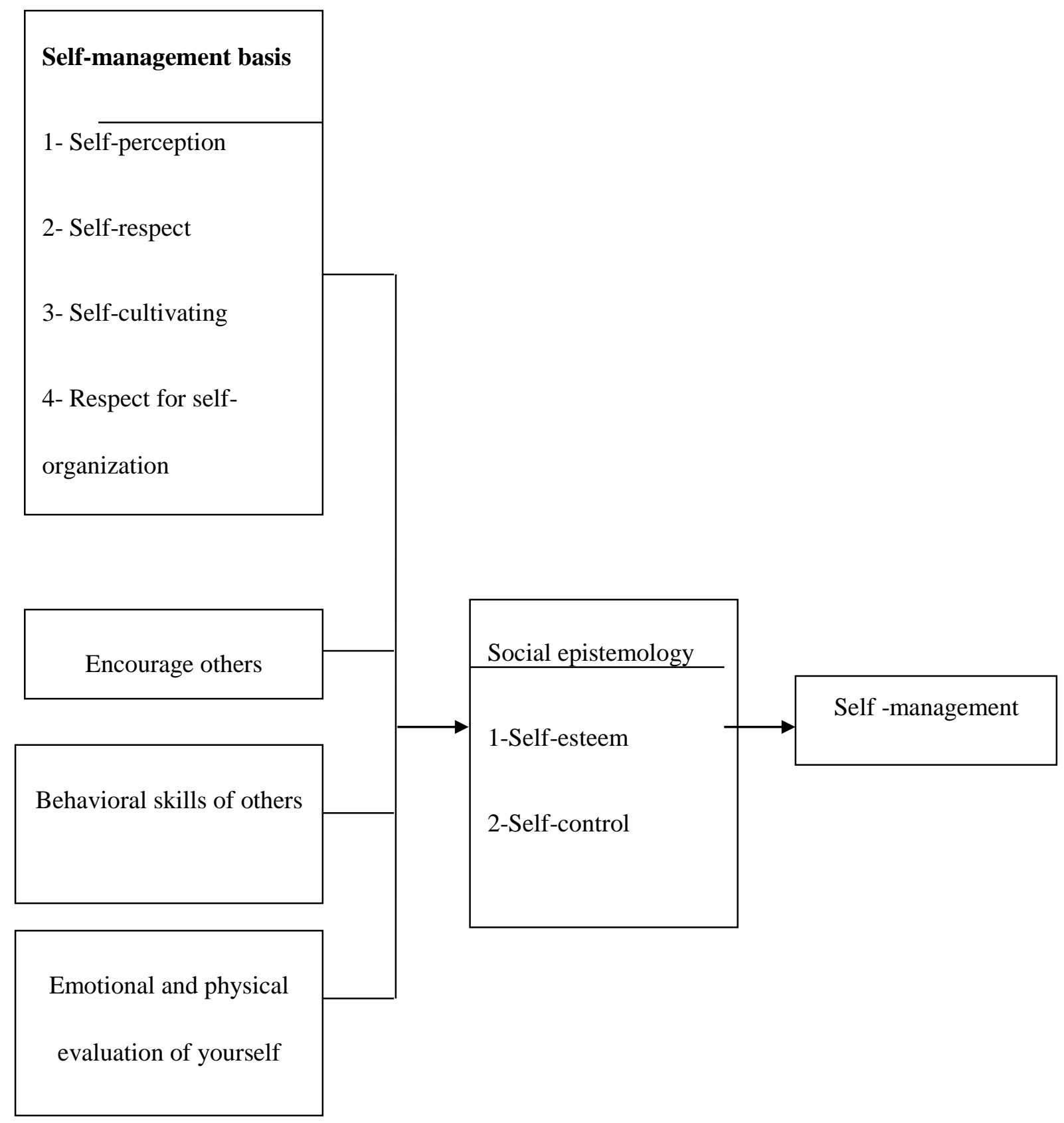

Figure 4: Self-management

\section{Discussion and Conclusion}

Given the tight competition in today's world, human resources are the most important competitive advantage for organizations. In this paper, some of the alternatives to centralized management have been addressed, each of which is interacting and interacting sequentially. Managers can implement these programs by giving them the freedom to act and provide them with sufficient authority to provide employees with control over their own growth and progress, to do things with commitment and without the need for centralized management. Considering that the use of appropriate managers is one of the most pressing challenges faced by organizations in the present era, there are many ways to design a rigorous and systematic replacement program to estimate and provide future requirements for organizations in managing change. Obviously, the success of these strategies involves the use of credible techniques that can create the required capabilities in individuals and enable them to solve organizational problems and advance the organization towards excellence. The mentioned 
patterns, if done correctly, can be used as a model for the success of the centralized management of the organization.

\section{References}

Abbas Zadegan Mohammad, Hassanzadeh Sudabeh. 2006 Empowering a New Approach in Management, Management Suite, No. 112.

Abdollahi, Bijan. 2006 The role of self-efficacy in employee empowerment, Tadbir Monthly, Eighteenth, No. 168.

Abrahamid, Christ. 2005. Authorizing Authorities and Investigating their Effects on Organizations, Journal of Information, Education and Research, Spring and Summer.

Alvarez Kaye, Eduardo, Salas and Christian. 2004. An integrated model of training evaluation and effectiveness, Human Resource Development Review, V. 13, No 4, p 389.

Baldwin, T.T \& Ford, J.K. 1988. Transfer of Training: A Review and Direction for Future Research. personnel psychology, vol. 41, pp63- 105.

Bandura A. 1989. Human agency in social cognition theory, American Psychologist; 44(9):1175 - 84

Bandura, A. 1989. Regulation of Cognitive Processes Through Perceived Self-Efficacy. Developmental Psychology: 729-35.

Based on Betts and susan M.Hailfman. 1985. organization culture: theory, definitions,and dimension, Paper presented at the national AIDS conference Lasvegas, Nov 1985.

Cengiz Yilmaz ,Ercan Ergun. 2008. Emotion serves to decouple stimulus and response, Journal of World Business, 43: 290-306

Connelly, C.E \& Kelloway, E.K. 2009. Predictors of Employees, Perceptions of Knowledge Sharing Cultures, Leadership and Organization Development Journal, VOL24,no 5 ,p294

Deal, TE. Kennedy AA. 2000. The New Corporate Cultures: Revitalizing the Workplace after Downsizing, Mergers, and Reengineering. Perseus Publishing: Cambridge, MA. Publication Year.

Gassari, Jamshid. 2009 New Human Disease Illness, Tadbir Monthly, Year 19, Issue 201.

Gordon, G. 2001. Industry determinants of organizational culture, Academy of management review, 396-415.

Holton ,E.F.III, Bates .R.A, Seyle . D.L, \& Carvalho .M.B. 1997. Toward construct validation of a transfer climate instrument, Human Resource Development Quarterly, vol 8 , no $2, \mathrm{p} 95$.

Holton.E.F.III, Bates. R.A, \& Ruona Wendy.E.A. 2000. The development of a generalized learning transfer system inventory, Human Resource Development Quarterly, vol 8, no 4, p 333.

Hopkins, Andrew. 2006. Department of Sociology, in the Faculty of Arts and National Research Centre, Safety Science, 44, 875-889

Khadivi, Asadollah. 2006 National and Organizational Culture Management, Information \& Education Quarterly, Spring \& Summer. 
M. Lemon, P.S. Sahota. 2005. International Ecotechnology Research Centre, School of Industrial and Manufacturing Science, Cranfield University, Cranfield.

Pal Herthis, Kenneth Blanchard. 2007 Management of Organizational Behavior, Translation by Dr. Ali Ali Sabz, Amir Kabir Publishing House, 29th Edition.

Peter A. Creed, Kim Lehmann, Michelle Hood. 2009. The relationship between core selfevaluations, employment commitment and well-being in the unemployed .Personality and Individual Differences, 47( 4): 310-5.

Rasouli, Reza 2005. The Relationship between Employee Empowerment and Job Satisfaction of Job Stress and Organizational Commitment, Management Message Nos. 15 and 16, pp. 165-194.

Rouiller, J.Z, \& Goldstein, I.L. 2007. The Relationship between organizational transfer climate and positive transfer of training, Human Development Quarterly, vol 4, no 4, p 95.

Sai On Cheung, Peter S.P. Wong, Ada W.Y. Wu. 2010. Embodying learning effect in performance prediction, International Journal of Project Management, 24(3): 207-215.

Sally E. Thorno , Arminee Kazanjian, Michael I. MacEntee. 2001. Journal of Aging Studies, $15,271-283$

Schein, EH. 1984. Coming to a new awareness of organization culture, Management Review, 25(2):3-16.

Walker, Carroll. 2002. Watch out for novice directors, translated by Seyyed Rahi Sadat Mousavi, Managing Editorial Magazine, No. 19.

Weiss, H. M. (Ed). 2005. Affect at work: Collaborations of basic and organizational research, Journal of Aging Studies, 35, 211-233. 